\title{
The Role and Effectiveness of School-Based Extra-Curricular Interventions on Children's Health and HIV Related Behaviour: The Case Study of Soul Buddyz Clubs Programme in South Africa
}

Lebohang Letsela ( $\sim$ lebohang.letsela@gmail.com)

Soul City Institute for Social Justice https://orcid.org/0000-0003-4290-5871

Michael Jana

University of the Witwatersrand

Rebecca Pursell-Gotz

Research \& Training for Heath Development

Phinah Kodisang

Soul City Institute for Social Justice

Renay Weiner

Research \& Training for Health \&Development

\section{Research article}

Keywords: Soul Buddyz Club, extracurricular, medical male circumcision, school-based HIV prevention programme, South Africa

Posted Date: March 31st, 2021

DOI: https://doi.org/10.21203/rs.3.rs-368795/v1

License: (c) (1) This work is licensed under a Creative Commons Attribution 4.0 International License. Read Full License

Version of Record: A version of this preprint was published at BMC Public Health on December 1st, 2021. See the published version at https://doi.org/10.1186/s12889-021-12281-8. 


\section{Abstract}

This paper sought to examine the role and effectiveness of an extra-curricular school based programme, Soul Buddyz Clubs (SBC) on HIV knowledge, attitudes, behaviours and biomedical outcomes. Secondary data analysis was performed on survey data of a nationally representative sample that was restricted to 10 -14-year-old males and females, using bivariate and multivariate methods in Stata14. Fifteen focus group discussions and 24 in-depth interviews conducted with SBC members, programme implementers and stakeholders in five provinces were analysed using thematic analysis in ATLAS.ti. The results indicated that $12 \%$ of respondents were exposed to SBC. Children exposed to SBC were more likely to be medically circumcised (AOR 2.38 ; $95 \% \mathrm{Cl}$ 1.29 -4.40, $\mathrm{p}=0.006$ ), had correct HIV knowledge (AOR 2.21; $95 \% \mathrm{Cl} 1.36-3.57, \mathrm{p}<0.001$ ) and had less stigmatising attitudes (AOR 0.54; $95 \% \mathrm{Cl} 0.31-0.93$, $\mathrm{p}=0.025)$ - in comparison to those not exposed. Qualitative findings also supported some of the quantitative results. SBC members reported having learnt about HIV prevention life skills, including condom use, positive attitudes towards people living with HIV, and alcohol abuse. Participation in SBC is associated with accessing biomedical HIV prevention services, specifically MMC, correct HIV prevention knowledge and less stigmatizing attitudes. This paper demonstrates the effectiveness of a school-based extracurricular intervention using a club approach targeting boys and girls ages 10-14 years on some of the key HIV prevention biomarkers as well as knowledge and attitudes. The article suggests that extra-curricular interventions can form an effective component of school-based comprehensive sexuality education in preventing HIV and promoting medical male circumcision.

\section{Background}

In Eastern and Southern Africa, evidence suggests that adolescents (10-19 years) and young people (10-24 years) are still heavily affected by HIV/AIDS. In 2017, adolescents and young people accounted for $37 \%$ of all new HIV infections and $15 \%$ of all people living with HIV [1]. Overall AIDS-related deaths have also increased by $50 \%$ among adolescents and young people between 2005 and 2017, despite the overall number of AIDS related deaths declining by $48 \%$ during the same period [1].

In South Africa, about 260,000 children aged 0 to 14 years lived with HIV in 2018 . HIV prevalence among young women (15-24 years) was significantly higher (11.3\%) than among young men (3.7\%) signifying the vulnerability of girls to the HIV pandemic [2]. This HIV burden among adolescents and young people comes in the context of limited access to HIV and SRHR services among this age group [1]. Any effort aimed at addressing HIV therefore needs to target this age group if it is to achieve such milestones as the SDG of ending HIV epidemic by 2030 [3].

For over two decades, the Department of Basic Education in South Africa has been implementing HIV education in schools through various interventions notably the institutionalisation of Life Skills and Life Orientation as part of the curriculum. The continued increase in HIV incidence among young people however indicates complexities in these interventions in addressing HIV risk among children and young people [4]. Visser has indicated that for school-based HIV prevention strategies to be effective, they need to go beyond educating the individual to understanding young people's sexual risk behaviour and the underlying drivers for these behaviours [4]. This includes addressing interpersonal and community factors such as improving child-parent communication, peer group norms, addressing substance abuse, and improving gender norms. This is consistent with behaviour change theories within the ecological approach such as the Social Identity Theory that emphasizes the importance of social norms in determining behaviour change [4, 5, 6]. Child-focused interventions that complement the curriculum-based interventions while guided by these social and behaviour change theories thereforehave the potential to tackle these drivers of adolescent behaviours. Save the Children International advises that when programming for children, it is imperative to put the child at the center of all programming [7]. There is a growing recognition that, as children transition into adulthood especially in high risk situations such as HIV/AIDS, they need safe spaces where they can communicate, socialize, learn and practice life skills and receive psychosocial support [8-12].

The Soul Buddyz Clubs (SBC) programme is one such programme that addresses interpersonal and community factors and gives voice to and promotes action by and for children's health and well-being. Soul Buddyz Clubs are school-based and target primary school preteens and young adolescents. They emerged from a health and development communication perspective with the strategic goal of empowering children through education and life skills, increasing their efficacy to deal with adolescent sexuality and HIV prevention, and becoming agents of change, embedding the principle of child participation. As an extra-curricular activity, the SBC activities are aimed at increasing knowledge and skills about health and wellbeing; strengthening the existing CSE curriculum taught at schools, supported by volunteer facilitators (educators at schools) where the clubs are implemented [13, 14]. The role of the teachers as facilitators of the clubs has been fundamental to its success and sustainability since 2003 when the clubs were initiated. The clubs provide learners with edutainment that allows them to have fun whilst learning; promoting positive attitudes and behaviours that relate to HIV, such as self-efficacy for safer sexual behaviour, condom use, gender based violence and alcohol and drug use [15]. Club activities range from regular after-school club meetings, discussions and debates on important themes, competitions and projects on topics of interest including HIV/AIDS treatment and stigma and discrimination; Sexual and Reproductive Health; Healthy lifestyle (nutrition, diet and physical activity); Medical Male Circumcision; Tuberculosis, Bullying; and Community participation. Facilitators are provided with training as well as additional resources and materials, including booklets, magazines, and posters, which are used to steer these discussions [14]. The clubs promote action by children facilitating their ability to organise themselves and be agents of change for children's issues.

Existing literature on school based programmes aimed at improving the sexual and reproductive health of adolescents indicate that school or communitybased sexuality and HIV/AIDS education programmes increase knowledge, may reduce the number of sexual partners and increase condom and contraceptive use [16-18]. There are also reported improvements in attitudes towards people living with HIV/AIDS, intention to abstain or use a condom as well as self-efficacy for condom use; increases in talking to others (friends, peers/ parents/ boyfriend/girlfriend) about sexual risk and delayed sexual debut $[17,19]$. Contrary to fears expressed by parents, school based SRHR programme do not lead to early sexual debut or increased sexual activity [20-23]. A review by Mason-Jones et al. revealed that combined (sexual and reproductive) educational and incentive-based programmes had a positive effect on Sexually Transmitted Infections (STIs) (herpes simplex virus infection) [24]. Ross et al. indicated that incentive based interventions are likely to reduce adolescent pregnancy[19]. 
While there are several programmes for adolescents in South Africa (e.g. DREAMS; YOLO, loveLife), there is a gap in programmes targeting 10-14-year olds. SBC is one of the few established programmes that targets this age group, a key age to target prevention, both because the majority have not yet begun sexual activity and since there is increasing evidence that sexual risk and vulnerability is occurring at a younger age. For example, the HSRC survey found that sexual debut $<15$ years increased from $8.5 \%$ in 2008 to $13,6 \%$ in 2017 . This is the case for both males and females: from $11.3-19.5 \%$ for males and $5,9 \%$ to $7,6 \%$ in females [25]. Furthermore, sexual coercion associated with sexual debut has been an issue of concern as highlighted in a study in KwaZulu-Natal by Maharaj \& Munthree, which found that nearly $46 \%$ of all adolescent girls and young women (14-24 years) reported that their first sexual encounter had been coerced and this group were more likely to have had an STI or unintended pregnancy [26].

There is paucity of evidence on the effectiveness of extra-curricular school-based programmes in promoting HIV prevention. A soccer-based programme implemented in Uganda and Zimbabwe that aimed to promote VMMC among schoolboys reported increases in male circumcision (10\% and 26\%) [27-28] as well as almost three times increased likelihoods to do VMMC [29]. Studies that documented support required by adolescents affected by HIV/ AIDS in schools revealed that within the context of high rates of psychological, behavioural and emotional problems among the youth, support by teachers', peers, the general school environment amidst experiences of discrimination, social exclusion, labelling and bullying in school was not adequate[30-31].

The objective of this paper is to contribute to the body of knowledge on the role and effectiveness of extracurricular school based programmes increasing in HIV knowledge, shifting attitudes and changing practices, as well as biomedical outcomes among children. The paper further seeks to show the value of participatory interventions that are child centred and provide an open and interactive environment while addressing HIV risk and life skills.

\section{Methods}

The paper used a mixed methods approach drawing on and integrating data from quantitative and qualitative sources. The quantitative data source was the SABSSM V, 2017 on which secondary analysis was performed to measure behavioural outcomes of the SBC programme over time. This survey was a nationally representative, cross-sectional study of males and females of all ages living in South Africa conducted between 2017 and 2018 , and for this study, data for the 10-14-year-old age group was analysed. Details on the SABSSM survey methodology have been described elsewhere [25]. Overall exposure to the Soul Buddyz Clubs Programme was measured through a combination of the following three questions from the survey "Have you ever belonged to a Soul Buddyz Club?" and if yes, for how long. All respondents, regardless of their Soul Buddyz Club membership were asked, "Have you read any of the following Soul Buddyz Club booklets in the past 12 months?" (list shown in Table 1).

Table 1

Soul Buddyz Club Materials

\begin{tabular}{|ll|}
\hline SBC Material & Topic of focus \\
\hline The Zone & Sexual and Reproductive Health: HPV vaccine \\
\cline { 2 - 3 } & Healthy living: healthy eating \\
& MMC \\
& Safety on the road \\
& Relationships, learning about the brain, Tobacco \\
& GBV, bullying, alcohol, personal development (saving/ starting business) \\
\hline Unit Guides & Alcohol: alcohol \& drug free school \\
& HIV stigma reduction, acceptance, and treatment adherence \\
Posters & TB, alcohol (alcohol free schools), HIV (stigma), drug usage \\
\hline
\end{tabular}

The analysis was restricted to and based on a weighted sample size of 2198,10 to 14-year olds. Population weights based on province, sex, age, and race were used to account for the complex survey design and non-response, and weighted data analysis was implemented using "svyset" in Stata. Weights were applied according to the SABSSM V schedule to account for non-respondents and to mitigate against the selection bias inherent in the sampling procedure [25]. Bivariate and multivariate analyses were conducted to determine the impact of exposure to SBC on knowledge, behaviours and biomedical indicators. Specifically the following outcomes were measured :sexual behaviours (ever having sex, condom use at first sex), HIV knowledge and stigmatising attitudes, and as well as HIV testing and medical male circumcision uptake. Bivariate (chi-square test of significance for frequency tables and cross tabulations) and multivariate analysis included logistic regression and propensity score adjusted models (PSM). Sociodemographic variables such as age, sex, level of education (grade), province and exposure to other media were used as controls and matching variables. The results of the final logistic regression models are reported using Adjusted Odds Ratios (AORs) and 95\% confidence intervals (Cls). The exposure variable was fitted in all the models.

Qualitative data were generated from a process evaluation study that was conducted with SBC members, programme implementers and stakeholders in five provinces in South Africa in 2018. A total of 10 focus group discussions with SBC boys and girls (some separately and some mixed) aged 10 to 14 years, five FGDs with SBC fieldworkers and 24 in-depth interviews with SBC facilitators and key informants across the five provinces were held to document the quality of implementation, lessons learnt and whether the objectives were met. Qualitative data were analysed using thematic analysis in ATLAS.ti and triangulated through comparing emerging themes as well as consistent findings across the data sets. 
Ethical approval was received from the HSRC Ethics Committee (Protocol no 4/18/07/18) to undertake the qualitative research with learners in schools. The survey was approved by the HSRC Research Ethics Committee (REC: 4/18/11/15) and reviewed in accordance with CDC human research protection procedures.

\section{Limitations}

The survey was a cross sectional study design which often cannot determine a temporal relationship. Although respondents were asked if they had belonged to a club in the last 12 months, some interventions such as MMC may have taken place before membership. Few observations to measure some of the key programmatic outcomes notably bullying and teen pregnancy meant these outcomes could not be fully assessed.

\section{Results}

\section{Reach and Relevance}

The sociodemographic characteristics of the sample are presented in Table 2 - total sample of 2198 . The mean age of respondents was 13 years (Standard Deviation: $S D=0.82)$. There were slightly more males $(51 \%)$ than females $(49 \%)$. There was a significant difference in age with more $13-14-y e a r$ olds $(70 \%)$ than $10-12$ year olds $(30 \%)(p=0.004)$ as well as sex $(p=0.01)$ between those exposed and not exposed to SBC $(60 \%$ females and $40 \%$ males). A quarter had completed grade 5 . There were significantly more respondents with grade 7 (last year of primary school) amongst the exposed (4\%) compared to those not exposed $(22 \%$ in grade 5$)(p=0.007)$.

The survey indicated $12 \%$ of the 10-14-year olds respondents were exposed to Soul Buddyz clubs and its booklets for over a year (11\% $=354256)$. More respondents aged $13-14$ years $(8.9 \% \mathrm{~N}=248259)$ than $10-12$ years $(3.8 \% \mathrm{~N}=105998)$ were reached with the programme. Reach was slightly higher among females $(7.6 \% \mathrm{n}=211997)$ than males $(5.1 \% \mathrm{n}=142 \mathrm{261})$. Four percent of respondents, equating to 108256 people, reported that they had ever belonged to a SBC. Most respondents who had ever belonged to a SBC indicated that they were part of an SBC for one year $(54 \% \mathrm{~N}=55490)$. 
Table 2

Socio-demographic characteristics of the SBC members vs non members

\begin{tabular}{|c|c|c|c|c|c|c|c|}
\hline & \multicolumn{2}{|c|}{ Exposed to SBC } & \multicolumn{2}{|c|}{ Unexposed to SBC } & \multicolumn{2}{|l|}{ Total } & \multirow[t]{2}{*}{ P-value } \\
\hline & No. & $\%$ & No. & $\%$ & No. & $\%$ & \\
\hline \multicolumn{8}{|l|}{ Age } \\
\hline $10-12$ years & 78 & $30 \%$ & 746 & $41 \%$ & 832 & $40 \%$ & \multirow[t]{3}{*}{0.004} \\
\hline $13-14$ years & 182 & $70 \%$ & 1073 & $59 \%$ & 1247 & $60 \%$ & \\
\hline Total & 260 & 100.0 & 1819 & 100.0 & 2079 & 100.0 & \\
\hline \multicolumn{8}{|l|}{ Sex } \\
\hline Male & 104 & $40 \%$ & 928 & $51 \%$ & 1034 & 49.7 & \multirow[t]{3}{*}{0.01} \\
\hline Female & 156 & $60 \%$ & 891 & $49 \%$ & 1045 & 50.3 & \\
\hline Total & 260 & 100.0 & 1819 & 100.0 & 2079 & 100.0 & \\
\hline \multicolumn{8}{|c|}{ Population group } \\
\hline Black African & 229 & 1 & 1510 & $83 \%$ & 1746 & $84 \%$ & \multirow[t]{5}{*}{0.27} \\
\hline White & 8 & 0 & 109 & $6 \%$ & 104 & $5 \%$ & \\
\hline Coloured & 18 & 0 & 164 & $9 \%$ & 187 & $9 \%$ & \\
\hline Indian/Asian & 5 & 0 & 36 & $2 \%$ & 42 & $2 \%$ & \\
\hline Total & 260 & 100.0 & 1819 & 100.0 & 2079 & 100.0 & \\
\hline \multicolumn{8}{|l|}{ Province } \\
\hline Eastern Cape & 23 & $9 \%$ & 255 & $14 \%$ & 291 & $14 \%$ & \multirow[t]{10}{*}{0.07} \\
\hline Free State & 18 & $7 \%$ & 109 & $6 \%$ & 125 & $6 \%$ & \\
\hline Gauteng & 81 & $31 \%$ & 364 & $20 \%$ & 437 & $21 \%$ & \\
\hline KwaZulu-Natal & 52 & $20 \%$ & 400 & $22 \%$ & 457 & $22 \%$ & \\
\hline Limpopo & 29 & $11 \%$ & 236 & $13 \%$ & 249 & $12 \%$ & \\
\hline Mpumalanga & 10 & $4 \%$ & 109 & $6 \%$ & 125 & $6 \%$ & \\
\hline North West & 23 & $9 \%$ & 127 & $7 \%$ & 146 & $7 \%$ & \\
\hline Northern Cape & 5 & $2 \%$ & 36 & $2 \%$ & 42 & $2 \%$ & \\
\hline Western Cape & 18 & $7 \%$ & 182 & $10 \%$ & 208 & $10 \%$ & \\
\hline Total & 260 & 100.0 & 1819 & 100.0 & 2079 & 100.0 & \\
\hline \multicolumn{8}{|l|}{ Grade } \\
\hline Grade 1 & 5 & $2 \%$ & 18 & $1 \%$ & 20 & $1 \%$ & \multirow[t]{9}{*}{0.007} \\
\hline Grade 2 & 5 & $2 \%$ & 54 & $3 \%$ & 41 & $2 \%$ & \\
\hline Grade 3 & 5 & $2 \%$ & 143 & $8 \%$ & 143 & $7 \%$ & \\
\hline Grade 4 & 31 & $12 \%$ & 286 & $16 \%$ & 327 & $16 \%$ & \\
\hline Grade 5 & 59 & $23 \%$ & 447 & $25 \%$ & 511 & $25 \%$ & \\
\hline Grade 6 & 52 & $20 \%$ & 411 & $23 \%$ & 470 & $23 \%$ & \\
\hline Grade 7 & 80 & $31 \%$ & 321 & $18 \%$ & 409 & $20 \%$ & \\
\hline Grade 8 & 21 & $8 \%$ & 107 & $6 \%$ & 123 & $6 \%$ & \\
\hline Total & 258 & 100.0 & 1786 & 100.0 & 2044 & 100.0 & \\
\hline
\end{tabular}

There was strong qualitative evidence supporting the relevance of the programme. Children live in a context where there is drug and alcohol abuse, sexual abuse, lack of communication between children and their parents, HIV and AIDS and exposure to unsafe places. By speaking directly to these issues, SBC was deemed to be relevant as illustrated in the quote below:

Figure 1: SBC FGD, girls 10-12 years, Gauteng, February 2019 
The picture above illustrates the perceptions of how SBC activities responded to the health environment of the children who participated in the FGDs. The picture talks about SBC school sessions to discuss the effects of alcohol, and visits to local taverns to discourage sale of alcohol to children. The quotation below further illustrates the relevance of SBC:

'We talk about having to be responsible towards others. We talk about everything other people have done to us. We go to the garden every day and talk about soul buddyz. Every Tuesday they give us homework to do. We have learnt a lot of things from Soul buddyz.' SBC FGD mixed 10-12 year olds, Gauteng, January 2019

Key aspects of success and sustained participation include that the clubs are child-led, provide peer support, are contextualised to the issues at hand and engage a passionate facilitator that is approachable and recognises the contribution of young people to their own development, and as change agents in their own lives. The relationships between facilitators and the Club members was also identified as a critical success factor. Where club members felt that they could trust facilitators, they felt that they could disclose things to the facilitator, and they would get help. Club members had the following to say about facilitators:

"I like them - they understand us". SBC FGD mixed 10-12 year olds, Western Cape, February2019 
Table 3

Associations between socio - demographic characteristics, HIV knowledge and stigma, MMC and HIV testing among SBC membership

\begin{tabular}{|c|c|c|c|c|c|c|c|c|c|c|c|c|}
\hline & \multicolumn{3}{|c|}{$\begin{array}{l}\text { Correct HIV prevention } \\
\text { knowledge }\end{array}$} & \multicolumn{3}{|c|}{$\begin{array}{l}\text { Medical Male } \\
\text { Circumcision }\end{array}$} & \multicolumn{3}{|c|}{ Recent HIV test } & \multicolumn{3}{|c|}{ HIV stigmatizing attitudes } \\
\hline & yes & no & $\mathrm{p}$ value & yes & no & $\mathrm{p}$ value & yes & no & $p$ value & $\begin{array}{l}\text { Has } \\
\text { stigma }\end{array}$ & $\begin{array}{l}\text { No } \\
\text { stigma }\end{array}$ & $\mathrm{p}$ value \\
\hline \multicolumn{13}{|l|}{ Age } \\
\hline $10-12$ years & $68 \%$ & $32 \%$ & \multirow{2}{*}{$\begin{array}{l}n=2198 \\
p=.0002\end{array}$} & $32 \%$ & $68 \%$ & \multirow{2}{*}{$\begin{array}{l}n=1026 \\
p=.43\end{array}$} & $17 \%$ & $83 \%$ & \multirow{2}{*}{$\begin{array}{l}n=1985 \\
p=.06\end{array}$} & $25 \%$ & $75 \%$ & \multirow{2}{*}{$\begin{array}{l}n=2069 \\
p \\
=.0002\end{array}$} \\
\hline $13-14$ years & $77 \%$ & $23 \%$ & & $36 \%$ & $64 \%$ & & $22 \%$ & $78 \%$ & & $16 \%$ & $84 \%$ & \\
\hline \multicolumn{13}{|l|}{ Sex } \\
\hline Male & $69 \%$ & $31 \%$ & \multirow{2}{*}{$\begin{array}{l}\mathrm{n}=2198 \mathrm{p} \\
=.003\end{array}$} & \multirow{2}{*}{\multicolumn{3}{|c|}{ N/A - only males }} & $23 \%$ & $77 \%$ & \multirow{2}{*}{$\begin{array}{l}\mathrm{n}=1985 \\
\mathrm{p}=.003\end{array}$} & $20 \%$ & $80 \%$ & \multirow{2}{*}{$\begin{array}{l}n=2069 \\
p=.84\end{array}$} \\
\hline Female & $77 \%$ & $23 \%$ & & & & & $16 \%$ & $84 \%$ & & $81 \%$ & $19 \%$ & \\
\hline \multirow[t]{2}{*}{$\begin{array}{l}\text { Correct HIV prevention } \\
\text { knowledge }\end{array}$} & \multicolumn{2}{|c|}{$\begin{array}{l}\text { Exposed to } \\
\text { SBC }\end{array}$} & \multicolumn{2}{|c|}{ Unexposed to SBC } & \multicolumn{2}{|l|}{ Total } & \multirow[t]{2}{*}{ P-value } & & & & & \\
\hline & No. & $\%$ & No. & $\%$ & No. & $\%$ & & & & & & \\
\hline No & 35 & $13 \%$ & 452 & $25 \%$ & 499 & $24 \%$ & \multirow[t]{3}{*}{0.0001} & & & & & \\
\hline Yes & 235 & $87 \%$ & 1357 & $75 \%$ & 1580 & $76 \%$ & & & & & & \\
\hline Total & 270 & 100 & 1809 & 100 & 2079 & 100 & & & & & & \\
\hline \multicolumn{13}{|l|}{$\begin{array}{l}\text { HIV stigmatizing } \\
\text { attitudes }\end{array}$} \\
\hline No stigma & 238 & $89 \%$ & 1413 & $79 \%$ & 1665 & $81 \%$ & \multirow[t]{3}{*}{0.005} & & & & & \\
\hline has stigma & 29 & $11 \%$ & 376 & $21 \%$ & 391 & $19 \%$ & & & & & & \\
\hline Total & 267 & 100 & 1789 & 100 & 2056 & 100 & & & & & & \\
\hline \multicolumn{13}{|l|}{ Ever had sex } \\
\hline No & 260 & $98 \%$ & 1754 & $99 \%$ & 1996 & $98 \%$ & \multirow[t]{3}{*}{0.33} & & & & & \\
\hline Yes & 5 & $2 \%$ & 18 & $1 \%$ & 41 & $2 \%$ & & & & & & \\
\hline Total & 265 & 100 & 1772 & 100 & 2037 & 100 & & & & & & \\
\hline Condom use at first se & & & & & & & & & & & & \\
\hline Did not & 2 & $49 \%$ & 8 & $46 \%$ & 11 & $47 \%$ & no p- & & & & & \\
\hline Used condom & 3 & $51 \%$ & 10 & $54 \%$ & 12 & $53 \%$ & & & & & & \\
\hline Total & 5 & 100 & 18 & 100 & 23 & 100 & & & & & & \\
\hline $\begin{array}{l}\text { Medical Male } \\
\text { Circumcision }\end{array}$ & & & & & & & & & & & & \\
\hline No & 46 & $45 \%$ & 625 & $68 \%$ & 674 & $66 \%$ & 0.0005 & & & & & \\
\hline Yes & 56 & $55 \%$ & 294 & $32 \%$ & 347 & $34 \%$ & & & & & & \\
\hline Total & 102 & 100 & 919 & 100 & 1021 & 100 & & & & & & \\
\hline Recent HIV test & & & & & & & & & & & & \\
\hline No & 187 & $73 \%$ & 1391 & $81 \%$ & 1579 & $80 \%$ & 0.02 & & & & & \\
\hline Yes & 69 & $27 \%$ & 326 & $19 \%$ & 395 & $20 \%$ & & & & & & \\
\hline Total & 257 & 100 & 1717 & 100 & 1974 & 100 & & & & & & \\
\hline HIV Status & & & & & & & & & & & & \\
\hline Negative & 186 & $98 \%$ & 1234 & $97 \%$ & 1418 & $97 \%$ & 0.97 & & & & & \\
\hline Positive & 4 & $2 \%$ & 38 & $3 \%$ & 44 & $3 \%$ & & & & & & \\
\hline Total & 190 & 100 & 1272 & 100 & 1462 & 100 & & & & & & \\
\hline
\end{tabular}




\section{Knowledge and psychosocial skills outcomes}

\section{HIV Knowledge}

Seventy-three percent of the respondents demonstrated correct HIV prevention knowledge measured using a knowledge scale which combined a set of questions on knowledge and perceptions of HIV/AIDS. A continuous HIV knowledge variable was created from 10 questions that looked at HIV knowledge. There was very strong evidence of an association between HIV knowledge and exposure to SBC with more respondents that were exposed to SBC reported having correct knowledge ( $87 \%)$ in comparison to those not exposed to the programme $(75 \%)(p<0.0001)$ (see Table). This finding was supported by the qualitative data with SBC members reporting that Soul Buddyz had improved their knowledge of HIV, how to protect themselves from contracting HIV, importance of condom use and identifying myths and misinformation about HIV such as that you can see by looking at someone if they have HIV as illustrated in the quotes below.

"I've learnt about sex and not to go too deep - not to have a sexual relationship". SBC FGD mixed 10-12 year olds, Western Cape, February 2019

"As a girl I learned not to be sexually active and to protect myself from boys (by not having sex or using condoms if I have sex)". SBC FGD mixed 10-12 year olds, Western Cape, February 2019

"The book (Soul Buddyz Booklet) tells us about looking after ourselves, gender and protecting ourselves from diseases like HIV and AIDS". SBC FGD, Boys, 10-12 years, Mpumalanga, November 2018

Soul Buddyz had also helped members identify and address myths and incorrect information about HIV and how HIV is acquired. Club members noted that one of the myths they had heard which was corrected through Soul Buddyz was:

"People get AIDS if they walk where someone spit and they have the sickness". SBC FGD mixed 10-12 years olds, Western Cape, February 2019

\section{HIV stigmatizing attitudes}

A total of $20 \%$ of teenagers reported to have stigmatizing attitudes measured using a knowledge scale which combined a set of questions on HIV/AIDS stigma. A continuous HIV stigma variable was created from six questions that looked at attitudes towards people living with HIV. There was strong evidence of association in reporting stigmatizing attitudes between those exposed to SBC and those unexposed $(p=0.005)$ with more respondents exposed to SBC reporting not having stigmatizing attitudes (89\%) compared to those not exposed (79\%) -(see Table 3). Club members from the qualitative study reported having learnt how people can be affected by stigma and misinformation. See Fig. 2 for a drawing depicting a discussion on HIV and AIDS and going to the hospital.

"Yes, some children are born HIV positive and when other children find out about their status they do not want to play with them. We play with those children because they are like the rest of us. We also play with them because we will also need help one day." SBC FGD mixed gender 10-12 years, KZN, January 2019.

Figure 2: SBC FGD, boys 10-12 years, Mpumalanga, November 2018

\section{Risky sexual behaviour}

\section{Sexual activity and condom use}

Some $1.5 \%$ respondents reported to have ever had sex. There was an insignificant association between sexual activity measured through "ever having sex" and exposure to SBC $p=0.33$ (see Table 3). Some 53\% respondents reported to have used a condom the first time they had sex. There were too few observations to measure the association between exposure to SBC and condom use at first sex. Qualitative findings further highlighted that children learned about safe sex and the use of condoms from SBCs.

"If someone has HIV you won't know just by looking at them. If you can't get tested then rather just use condoms. Yes, safe sex. They teach us about that in Soul Buddyz" SBC FGD, female 13-14 years, Western Cape, January 2019

\section{Access to biomedical intervention}

\section{Medical Male Circumcision}

Thirty four percent (34\%) of males reported having had MMC performed by a doctor. There was very strong evidence of an association between medical male circumcision and exposure to SBC $(p=0.0005)$. More males exposed to SBC reported being medically circumcised than those not exposed $(55 \%$ versus $32 \%)$ (see Table 3).

\section{HIV testing and status}

A total of $20 \%$ of the respondents reported to have been tested for HIV. There was evidence of an association between HIV testing and exposure to SBC ( $p=$ 0.02). More adolescents exposed to SBC (27\%) reported taking an HIV test compared to those not exposed to SBC (19\%). Moreover, some $3 \%$ respondents tested positive for HIV - fewer of those exposed to SBC tested negative $2 \%$ compared to $3 \%$ who were unexposed to SBC but this was not statistically significant $(p=0.97)$ (see Table 3$)$.

Multivariate analysis findings: The relationship between risky sexual behaviours, HIV status, MMC and exposure to SBC 
Table 4

Adjusted odds ratio for behavioural and biomedical outcomes in exposure to SBC estimated by logistic regression

\begin{tabular}{|c|c|c|c|c|c|c|}
\hline $\begin{array}{l}\text { Univariate regression OR } \\
(95 \% \mathrm{Cl})\end{array}$ & $\mathbf{N}$ & $\begin{array}{l}\text { Exposure to } \\
\text { SBC }\end{array}$ & $\begin{array}{l}\text { Unadjusted Odds } \\
\text { ratio }\end{array}$ & $\begin{array}{l}\text { Adjusted Odds } \\
\text { ratio' }\end{array}$ & $95 \% \mathrm{Cl}$ & $\begin{array}{l}\text { Sample } \\
\text { size }\end{array}$ \\
\hline
\end{tabular}

Confounding

variables

Correct HIV prevention

knowledge

$2.35^{*}(1.49-3.68) \quad 2.21 \quad 1.36-\quad 0.001 \quad 2079$

2079

Age

$\begin{array}{ll}13-14 \text { years } & 1.66^{\star \star *}(1.17-2.35) \\ 10-12 \text { years } & 0.60^{\star \star *}(0.43-0.85)\end{array}$

Province

Eastern Cape

$0.93^{\star \star}(0.39-2.19)$

Free State

$1.66^{\star \star}(0.75-3.69)$

Gauteng

2.32" (1.13-4.74)

KwaZulu-Natal

1.32 ** $(0.68-2.59)$

Limpopo

$1.24^{\star \star}(0.55-2.78)$

Mpumalanga

$0.96^{* \star}(0.41-2.25)$

North West

1.96 ** $(0.95-4.06)$

Northern Cape

$1.33^{\star \star}(0.63-2.83)$

Western Cape

$1 .-8 * *(0.46-2.56)$

\section{Grade}

Grade 1

$1.04^{\star \star}(0.19-5.55)$

Grade 2

$0.36^{\star *}(0.49-2.69)$

Grade 3

Grade 4

0.18" (0.03-1.01)

Grade 5

$0.43^{\star *}(0.08-2.35)$

Grade 6

0.50 ** $(0.09-2.72)$

Grade 7

Grade 8

$0.49 * *(0.09-2.61)$

0.96 ** $(0.18-5.09)$

$0.75^{\star \star}(0.12-4.82)$

\section{Exposure to other}

media

Yes

No

" $p<0.05$

* $p=0.001$

$\star * p>0.05$

*** $p<0.01$

-


The multivariate regression analysis models presented in Table 4 reveals that after controlling for age, sex, level of education, province and exposure to other media, SBC exposure was significantly associated with medical circumcision (AOR 2.38; 95\% Cl 1.29-4.40, $\mathrm{p}=0.006$ ), HIV knowledge (AOR 2.21; 95\%Cl 1.36$3.57, \mathrm{p}<0.001$ ) and less stigmatising attitudes (AOR $0.54 ; 95 \% \mathrm{Cl} 0.31-0.93, \mathrm{p}=0.006$ ). Addressing selection bias in trying to estimate the effect of the intervention, we conducted a PSM (see Table 5) - the PSM findings are consistent with the regression findings showing that the probability of having stigma is -0.09 percentage point ( $0.9 \%$ point) reduced; and a $0.26 \%$ point increase in doing MMC and $0.102 \%$ point increase in having correct HIV prevention knowledge, in the exposed as opposed to those unexposed.

Table 5

Propensity score matching treatment effect of exposure to SBC for behavioural and biomedical outcomes

\begin{tabular}{|c|c|c|c|c|c|}
\hline Average treatment effect & & $\%$ frequency & Coefficient & $95 \% \mathrm{Cl}$ & $P$ value \\
\hline \multirow[t]{2}{*}{ Correct HIV prevention knowledge } & SBC exposure & $15 \%$ & .102 & $0.101-0.103$ & $<0.0001$ \\
\hline & unexposed & $85 \%$ & & & \\
\hline \multirow[t]{2}{*}{ Medical Male Circumcision } & SBC exposure & $16 \%$ & .229 & $0.226-0.231$ & $<0.0001$ \\
\hline & unexposed & $84 \%$ & & & \\
\hline \multirow[t]{2}{*}{ HIV stigmatizing attitudes } & SBC exposure & $7 \%$ & -.092 & $(-) 0.093-(-) 0.091$ & $<0.0001$ \\
\hline & unexposed & $93 \%$ & & & \\
\hline \multirow[t]{2}{*}{ Recent HIV test } & SBC exposure & $17 \%$ & .056 & $0.054-0.057$ & $<0.0001$ \\
\hline & unexposed & $83 \%$ & & & \\
\hline \multirow[t]{2}{*}{ HIV Status (positive) } & SBC exposure & $13 \%$ & -.0040296 & $(-) 0.004-(-) 0.003$ & $<0.0001$ \\
\hline & unexposed & $87 \%$ & & & \\
\hline \multirow[t]{2}{*}{ Ever had sex } & SBC exposure & $21 \%$ & .008 & $0.007-0.008$ & $<0.0001$ \\
\hline & unexposed & $79 \%$ & & & \\
\hline \multirow[t]{2}{*}{ Ever consuming alcohol } & SBC exposure & $19 \%$ & .011 & $0.010-0.012$ & $<0.0001$ \\
\hline & unexposed & $81 \%$ & & & \\
\hline
\end{tabular}

Adjusting for age, sex, province and exposure to other media, adolescents exposed to SBC have a positive but insignificant association with HIV testing (AOR $1.4895 \% \mathrm{Cl} 0.97-2.25 \mathrm{p}=0.06$ ) and a negative HIV test outcome with $5 \%$ decreased (less) odds of being HIV positive compared to those not exposed (AOR $0.9595 \% \mathrm{Cl} 0.29-3.11, \mathrm{p}=0.93)$.

While, teenagers exposed to SBC have 1.44 odds of having had sex compared to those not exposed, this was statistically insignificant (AOR $1.4495 \% \mathrm{Cl}$ $0.42-4.88 ; p=0.56$ ). There were too few observations to draw any significant results for condom use at first sex among those exposed to SBC compared to those unexposed. In summary, this analysis has demonstrated that being a Soul Buddyz Club member has a positive effect on biomedical HIV prevention uptake specifically MMC and HIV testing, HIV prevention knowledge and HIV related stigma outcomes. Qualitative findings support some of these findings with SBC members indicating having learnt life skills related to HIV prevention through participation in the clubs.

\section{Discussion}

This paper has demonstrated the effectiveness of a school-based extracurricular intervention using a club approach targeting boys and girls ages $10-14$ years on some of the key HIV prevention biomarkers as well as knowledge and attitudes as previously demonstrated by previous studies [17, 19]. Various studies have examined the impact of a soccer-based programme in Uganda and Zimbabwe, that aimed to promote MMC among school boys and reported increases in the male circumcision ( $10 \%$ and $26 \%$ at first and second phase) [27-28] as well as almost three times increased odds of VMMC [29]. To our knowledge this is the first study to demonstrate the uptake of MMC among boys in relationship to an extramural in school programme. Given the previous lack of evidence in this area it is a significant finding.

The findings support previous studies that reported impact of CSE Programme on HIV prevention knowledge. The UNFPA evidence brief on the effectiveness of CSE in preventing HIV reports strong evidence that in-school CSE leads to improved knowledge, increased condom use, decrease in multiple partners, increase in self-efficacy for HIV protection, favourable attitudes to safer sex and delays in initiation of first sexual intercourse [32-33]. Similarly, there is evidence that school-based sexual and reproductive health programmes improve knowledge and reduce self-reported risk taking [16-19]. A retrospective study of the Soul Buddyz Club revealed that ex-SBC members are three times more likely to be HIV negative, twice more likely to have 1 sexual partner and use a condom at first sex 10 years later [15].

Additionally, a significant body of evidence also shows that CSE enables children and young people to develop accurate age appropriate knowledge, attitudes and skills that contribute to safe healthy positive relationships while also helping young people reflect on social norms, cultural values and beliefs in order to 
better understand and manage their relationships with peers, parents, teachers and other adults in their surroundings [34]. A barrier to classroom-based life orientation or CSE is that teachers are not always interested in the topic and/or trained to deliver the content. The Soul Buddyz model draws on volunteer teachers who are often passionate about the goals and aims of the programme, and undergo specific training in this regard. Further, there is evidence that shows the limited impact of curriculum-based life orientation interventions in South Africa on HIV/AIDS among young people for the past 20 years, and emphasize the need for interventions that go beyond educating an individual to addressing interpersonal and community factors [4]. The SBC Programme is modelled on addressing interpersonal and community factors such as, parent-child communication, peer group norms, addressing substance abuse, and improving gender norms. This paper therefore, using the case of the SBC Programme, demonstrates the potential for extra-curricular interventions to complement curricular interventions in influencing positive HIV behaviours and outcomes.

The value of SBC is in imparting health and social skills that encourage children to support each other, be agents of social change primarily in their school as well as increase their sense of self-worth and confidence [13]. Previous studies that documented support required by adolescents affected by HIV/AIDS in schools revealed that the school support by teachers', peers, the general school environment and the degree of discrimination, social exclusion, as well as labelling and bullying in school was not adequate, amidst high rates of psychological, behavioural and emotional problems among the youth [30-31]. This paper has demonstrated impact on HIV related stigma showing that children exposed to the programme have positive and caring attitudes towards people living with HIV.

The flexibility to adapt the programme based on the context in which it is implemented ensures that the programme responds to the needs of the young people enrolled in the clubs providing opportunities to address real-life challenges and concerns for these young people. This opportunity has helped club members to develop skills and knowledge which have contributed to reducing HIV related stigma and increased numbers of club members having undergone

MMC as compared to young people who were not club members. We believe this to be important for two reasons - it means a decline in the number of young boys who may have gone through a traditional circumcision school where there are a number of health risks, and an increase in the number of people who may choose MMC as a means of reducing the risk of HIV infection.

There were positive but insignificant findings on HIV testing and being HIV negative among those exposed to the programme. Continued work specifically focused and appropriate to this age group is required to encourage HIV testing particularly for sexually active young adolescents. There was also no impact on condom use at first sex, which may be due to the small sample size. On the other hand, this lack of impact or significant findings on HIV testing may be due to the design of the SBC programme and topics covered. For example, there may have not been more emphasis on HIV testing in the clubs given the age of the SBC members.

The presented evidence indicates that programmes such as the Soul Buddyz programme which are rooted in child participation principles and implemented as children's safe spaces to tackle social issues are effective in providing an opportunity for pupils to engage in difficult conversations, elicit peer support, develop skills to navigate social situations and enables children to make choices about their own future. Key aspects of success and sustained participation include that the clubs are child-led, provide peer support, are contextualised to the issues at hand and engage a passionate facilitator that is approachable and recognises the contribution of young people to their own development, and as change agents in their own lives [13]. Since under-resourced schools and communities typically lack access to extra-curricular activities, both due to the absence of facilities and resources, Soul Buddyz offers an enriching, fun and educational opportunity for children to belong and participate in positive activities, and supplements the existing content of the CSE curriculum taught in school classrooms in a non-threatening way. The clubs have demonstrated themselves to be powerful vehicles for engaging young people aged 10-14 years in solving their own problems, in sharing knowledge about HIV and sexual behaviour and in discussing social issues which place young people at risk of HIV infection.

\section{Conclusion}

There is a scantiness of evidence on the effectiveness of extra-curricular school-based programmes in promoting HIV prevention particularly among young people ages 10-14-year olds. This study fills this gap in knowledge on the role and success of school based programmes, particularly extra-curricular programmes on HIV knowledge, attitudes and practices, as well as MMC among South African children ages 10-14 years who were exposed to the Soul Buddyz Clubs Programme. It further builds on the initial work by Schmid et al. (2010) showing the unique value of SBC and how the programme has been implemented, which likely impacted observed programme outcomes. Overall, the paper builds on an emerging body of knowledge about the use of schoolbased extra-curricular programmes to work with at risk youth as part of HIV prevention and education through the use of SBCC.

The SBC program designers possibly needs to review and strengthen its messaging on HIV testing, teenage pregnancy, delaying sexual debut, and alcohol consumption. There is a need to design a rigorous evaluation study to appropriately measure SBC specific outcomes including bullying and teenage pregnancy. Continued support and implementation of programmes of this nature is essential, given that there are not many interventions targeting this age group, which are necessary as they are in the early delicate pubescence stage and can mould them into responsible adolescents. Further research specifically tailor designed to evaluate their impact focusing on all its outcome indicators of interest, including in the longer term should also be undertaken. More research on how and why these programmes work would also be useful to inform intervention design and implementation.

\section{Abbreviations}

SRHR - Sexual and Reproductive Health Rights

SDG - Sustainable Development Goals 
SBC - Soul Buddyz Clubs

CSE - Comprehensive Sexuality Education

GBV - Gender Based Violence

MMC - Medical Male Circumcision

VMMC - Voluntary Medical Male Circumcision

DREAMS- Determined, Resilient, Empowered, AIDS-free, Mentored and Safe

YOLO - You only Live Once

HSRC - Human Sciences research Council

SABSSM V - The fifth South African National HIV Prevalence, Incidence, Behaviour and Communication Survey

FGD - Focus Group Discussion

CDC - Centers for Disease Control and Prevention

UNFPA - United Nations Population Fund

SBCC - Social and Behaviour Change Communication

\section{Declarations}

\section{Ethics approval and consent to participate}

The study received ethical clearance from the Human Sciences Research Council Research Ethics Committee (REC 4/18/11/15). It was reviewed in accordance with Centers for Disease Control (CDC) human research protection procedures. Parental/ guardian informed written consent was received for all children younger than 18 years. The minor's assent were also obtained before participants took part in the study.

\section{Consent for publication}

Not Applicable.

\section{Availability of data and materials}

The raw data may be made available upon reasonable request from the corresponding authors.

\section{Competing interests}

The authors declare that they have no competing interests.

\section{Funding}

No specific funding was received for this paper. However, the HSRC from which the survey data which was used for secondary data analysis is from, received specific funding as reflected in their respective report (Simbayi et al., 2019)

\section{Authors' contributions}

LL, MJ, RP, PK, RY conceptualized the manuscript. LL led the quantitative data analysis and interpretation of the findings with support from an external epidemiologist. RW also reviewed the interpretation of the quantitative findings. MJ and RP led the qualitative data analysis and interpretation. LL and MJ led the literature review. LL led the writing of the manuscript with MJ supporting and also writing up part on the various sections. RP, PK, RW led the discussion section. RW provided overall oversight and made sure that the manuscript speaks to the outcomes of interest. All authors reviewed drafts of the manuscript. All authors have read and approved the manuscript.

\section{Acknowledgements}

Mr. Cornelius Nattey for assisting with secondary multivariate data analysis.

\section{References}

1. Govender K, Masebo WGB, Nyamaruze P, Cowden RG, Schunter BT, Bains A, 'HIV Prevention in Adolescents and Young People in the Eastern and Southern African Region: A Review of Key Challenges Impeding Actions for an Effective Response' in The Open AIDS Journal. 2018; 12 : 53-67.

2. The Joint United Nations Programme on HIV/AIDS (UNAIDS). Country Fact Sheet: South Africa 2018. https://www.unaids.org/en/regionscountries/countries/southafrica Accessed 12 June 2020

Page 12/14 
3. World Health Organization (WHO). Fact sheets on the sustainable development goals: health targets (2017).

https://www.euro.who.int/_data/assets/pdf_file/0006/348684/HIV-FINAL-11-Sept-2017.pdf?ua=1 Accessed 30 September 2020

4. Visser, M. 'Rethinking HIV-prevention for school-going young people based on current behaviour patterns' Journal of Social Aspects of HIV/AIDS. 2017; 14 (1): 64-76

5. Airhihenbuwe, $\mathrm{CO}$, Obregon R. A critical assessment of theories / models used in health communication for HIV/AIDS, Journal of Health Communication, 2000, 5: 5-15.

6. Darnton A. Reference report: An overview of behaviour change models and their uses. Government Social Research (GSR). 2008. https://assets.publishing.service.gov.uk/government/uploads/system/uploads/attachment_data/file/498065/Behaviour_change_reference_report_tcm69697.pdf Accessed 17 July 2020

7. Save the Children International (2009). Making it personal: a guide for master facilitators. A process-orientated approach to training: making it personal. https://resourcecentre.savethechildren.net/node/16780/pdf/making_it_personal_facilitator_guide_fin.pdf Accessed 17 July 2020

8. Karen A. 'Expanding Safe Spaces and Developing Skills for adolescent girls' Promoting Healthy, safe and Productive Transitions to Adulthood Brief no. 9. 2007. Population Council, Inc. http://citeseerx.ist.psu.edu/viewdoc/download?rep=rep1\&type=pdf\&doi=10.1.1.175.8209 Accessed 22 July 2020

9. The Children's Corner Visit Team. Malawi Children's Corners Situational Assessment. Technical Report. Published by the USAID ASSIST Project. 2016. Bethesda, MD: University Research Co., LLC (URC).

10. Baldwin W. 'Creating "safe spaces" for adolescent girls' in Promoting healthy, safe, and productive transitions to adulthood Series, Brief No. 9. (2011). The Population Council. https://www.popcouncil.org/uploads/pdfs/TABriefs/39_SafeSpaces.pdf Accessed 22 July 2020

11. Browne E. 'Child-friendly spaces for adolescent girls in emergency settings' in GSDRC Help Desk Research Report. (2013) http://www.gsdrc.org/docs/open/hdq932.pdf Accessed 22 July 2020

12. Gilliam M. 'From Intervention to Invitation: Reshaping Adolescent Sexual Health through Storytelling' in African Journal of Reproductive Health. 2012; 16(2): $189-196$

13. Schmid J, Wilson T, Taback R. Soul Buddyz Clubs: A social developmental International Social Work. 2010; 54 (2): $272-286$

14. Soul City Institute for Social Justice. Soul Buddyz Clubs. https://www.soulcity.org.za/mobilisation/soul-buddyz-club and https://www.soulcity.org.za/resources/materials/fact-sheets/soulcity-institute-soul-buddyz-club.pdf Accessed 20 November 2020

15. Johnson S, Magni S, Dube Z, Goldstein S. Extracurricular School-Based Social Change Communication Programme Associated with Reduced HIV Infection Among Young Women in South Africa. Journal of Health Communication. 2018; 00: 1-7

16. Kirby D, Coyle K. School-based Programmes to reduce sexual risk-taking behaviour. Children and Youth Services Review. $1997 ; 19$ (5/6): $415-436$

17. Gallant M, Maticka-Tyndale E. School-based HIV prevention Programme for African youth. Social Science \& Medicine. $2004 ; 58$ (7): $1337-1351$.

18. Sani AS, Abraham C, Denford S, Ball S. School-based sexual health education interventions to prevent STI/HIV in sub-Saharan Africa: a systematic review and meta-analysis. BMC Public Health. 2016; 16: 1069

19. Ross DA, Changaluchab J, Obasia IAN, Todda J, Plummera ML, Cleophas-Mazigec B. et al. Biological and behavioural impact of an adolescent sexual health intervention in Tanzania: a community-randomized trial. AIDS. 2007; 21:1943-1955

20. Kinsman J, Nakiyingi J, Kamali A, Carpenter L, Quigley M, Pool R, Whitworth J. Evaluation of a comprehensive school-based AIDS education programme in rural Masaka, Uganda. Health Education Research, 2001; 16: 85-100.

21. Harvey B, Stuart J, Swan T. Evaluation of a drama-in-education programme to increase AIDS awareness in South African high schools: A randomized community intervention trial. International Journal of STD \& AIDS. 2000; 11: 105-111.

22. Stanton BF, Li X, Kahihuata J, Fitzgerald AM, Neumbo S, Kanduuombe G. et al. Increased protected sex and abstinence among Namibian youth following a HIV risk-reduction intervention: A randomized, longitudinal study. AIDS. 1998; 12:2473-2480.

23. Shuey DA, Babishangire BB, Omiat S, Bangarukayo H. Increased sexual abstinence among in-school adolescents as a result of school health education in Soroti district, Uganda. Health Education Research. 1999; 14(3): 411-419.

24. Mason-Jones AJ, Sinclair D, Mathews C, Kagee A, Hillman A, Lombard C. School-based interventions for preventing HIV, sexually transmitted infections, and pregnancy in adolescents. Cochrane Database of Systematic Reviews. 2016; 11.

25. Simbayi LC, Zuma K, Zungu N, Moyo S, Marinda E, Jooste S. et al. South African National HIV Prevalence, Incidence, Behaviour and Communication Survey, 2017. Cape Town: HSRC Press. (2019) http://www.hsrc.ac.za/uploads/pageContent/10779/SABSSM\%20V.pdf Accessed 22 July 2020

26. Maharaj P, Munthree C. Coerced first sexual intercourse and selected reproductive health outcomes among young women in KwaZulu-Natal, South Africa. J Biosoc Sci. 2007; 39 (2): 231- 244

27. Miiro G, DeCelles J, Rutakumwa R, Nakiyingi-Miiro J, Muzira P, Ssembajjwe W, et al. Soccer-based promotion of voluntary medical male circumcision: A mixed-methods feasibility study with secondary students in Uganda. PLoS ONE. 2017; 12(10): e0185929.

28. DeCelles J, Hershow RB, Kaufman ZA, Gannett KR, Kombandeya T, Chaibva at al.. Process Evaluation of a Sport-Based Voluntary Medical Male Circumcision Demand-Creation Intervention in Bulawayo, Zimbabwe. Journal Acquir Immune Defic Syndr. 2016; 72: S304-S308

29. Kaufman ZA, DeCelles J, Bhauti K, Hershow RB, Weiss HA, Chaibva C, et al. A Sport-Based Intervention to Increase Uptake of Voluntary Medical Male Circumcision Among Adolescent Male Students: Results From the MCUTS 2 Cluster-Randomized Trial in Bulawayo, Zimbabwe. J Acquir Immune Defic Syndr. 2016;72 (4): S292-S298

30. Asikhia OA Mohangi. A case study of school support and the psychological, emotional and behavioural consequences of HIV and AIDS on adolescents, SAHARA-J: Journal of Social Aspects of HIV/AIDS. 2015; 12:1, 123-133

Page $13 / 14$ 
31. Campbell C, Andersen L, Mutsikiwa A, Madanhire C, Skovdal M, Nyamukapa C, Gregson S. Children's representations of school support for HIV-affected peers in rural Zimbabwe. BMC Public Health. 2014; 14:402

32. UNFPA ESARO. How effective is comprehensive sexuality education in preventing HIV? (2016) https://esaro.unfpa.org/sites/default/files/pubpdf/CSE\%20A4\%20FA\%20low\%20res\%20pages.pdf Accessed 23 September 2020

33. International Planned Parenthood Federation (IPPF). Deliver+Enable Toolkit: Scaling-up comprehensive sexuality education (CSE). (2016). https://www.ippf.org/sites/default/files/2018-03/IPPF\%20Deliver\%20and\%20Enable\%20-\%20CSE\%20Toolkit.pdf Accessed 23 September 2020

34. 34. United Nations Educational, Scientific and Cultural Organization (UNESCO). International technical guidance on sexuality education: An evidenceinformed approach (Revised edition). (2018). https://www.unfpa.org/sites/default/files/pub-pdf/ITGSE.pdf Accessed 23 September 2020

\section{Figures}

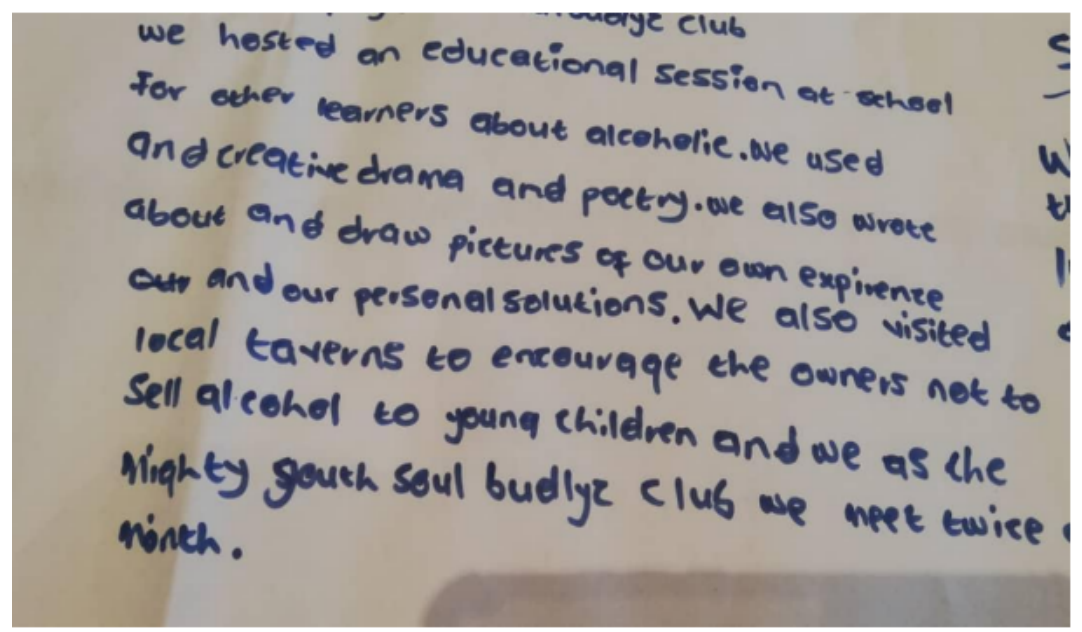

Figure 1

SBC FGD, girls 10-12 years, Gauteng, February 2019

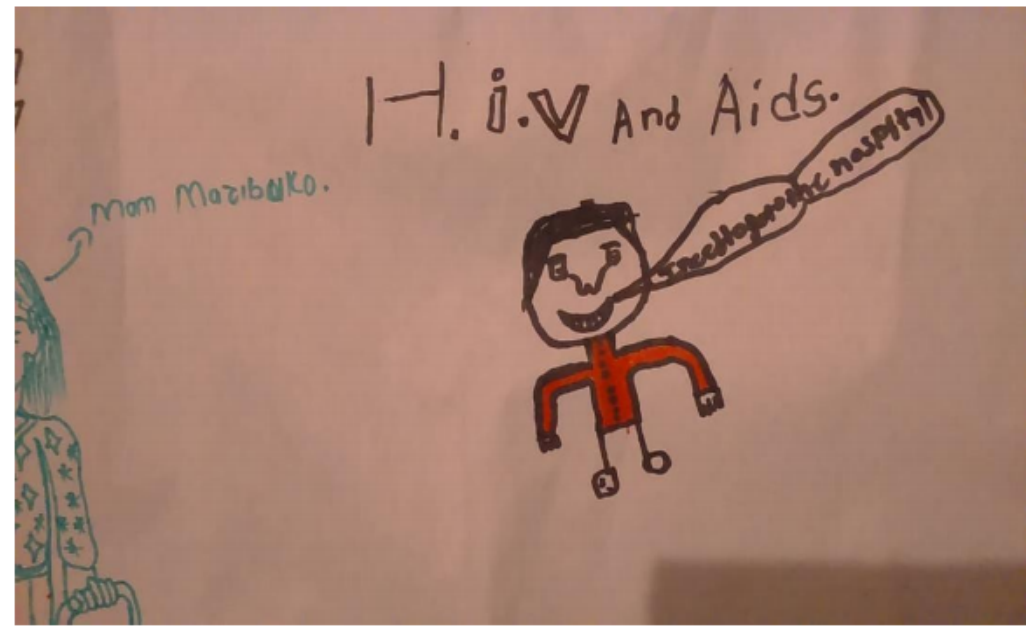

Figure 2

SBC FGD, boys 10-12 years, Mpumalanga, November 2018 